\title{
PROTEGENDO A BOCA DOS OUTROS: \\ A FEDERACÃO ODONTOLÓGICA LATINO-AMERICANA E O DESENVOLVIMENTO DA PROFISSÃO ODONTOLÓGICA NA AMÉRICA LATINA
}

IRANILSON BURITI OLIVEIRA*

UNIVERSIDADE FEDERAL DE CAMPINA GRANDE CAMPINA GRANDE - PARAÍBA - BRASIL

RESUMO

Este artigo analisa a criação da Federação Odontológica Latinoamericana, pensando-a dentro de um contexto de expansão do saber do dentista na sociedade, com a emergência de novas faculdades e novos profissionais da área. A partir da Nova História Cultural, e tendo como fontes os anais dos congressos latino-americanos que ocorreram nos anos 20 e os estatutos da Federação, este artigo põe em discussão as normas de controle e inspeção criados e postos em prática pela Federação Odontológica Latino-americana. Dessa forma, estudar a emergência de uma federação constitui uma maneira de refletir sobre as ações institucionalizadas de formação do cirurgião-dentista e como estas moldaram saberes e práticas da profissão ao longo do tempo.

Palavras-chave: Federação Odontológica Latino-americana; Associação odontológica; Cuidado bucal.

This article analyzes the creation of the Latin American Dental Federation, thinking it within a context of expanding the knowledge of dentists in society, with the emergence of new colleges and new professionals in the field. Based on the New Cultural History, and counting as the main research source the Annals of Latin American congresses that took place in the 1920s and the Federation's statutes, this article discusses the control and inspection rules created and put into practice by the Latin American Dental Federation. Thus, studying the emergence of a federation is a way of reflecting on the institutionalized methods of training the dentist and how these actions have shaped the knowledge and practices of the profession over time.

Keywords: Latin American Dental Federation; Dental association; Oral care 


\section{INTRODUCÃO}

Europa, século XVII. A organização de sociedades, ligas, associações e federações foi uma tendência que surgiu nesse contexto europeu, momento em que o desenvolvimento das ciências e das pesquisas contrastava acentuadamente com o ensino nas universidades, que seguia modelos ainda ligados a tradições medievalistas e a pensamentos não alinhados com as ideias emergentes na Modernidade. Aos poucos, em diversos países, trabalhadores de distintas categorias (médicos, dentistas, farmacêuticos) começaram a se organizar em associações com finalidades e objetivos diversos, dentre os quais protegerem-se de práticas charlatães e criar uma identidade ${ }^{1}$ profissional. Compreenda-se por identidade profissional aquela que é pensada nas malhas discursivas, produzida "em locais históricos e institucionais específicos, no interior de formações e práticas discursivas específicas, por estratégias e iniciativas específicas.”2

No sabor e calor dos acontecimentos que marcaram a Europa pós século XVII, as associações, como políticas de governamentalidade ${ }^{3}$, podem ser vistas e lidas como parte integrante do processo de institucionalização das profissões, ocorrido na formação do Estado moderno. Portanto, pensar uma federação odontológica constitui, também, refletir sobre as práticas institucionalizadas de formação do cirurgião-dentista e como estas moldaram saberes e práticas da profissão ao longo do tempo.

Desde o início do século XX, com a ampliação da odontologia de mercado (caráter mercadológico e monopolista das ações e da profissão $)^{4}$, que a boca e o sorriso ganham cada vez mais atenção. A boca, essa materialidade corpórea, é cada vez mais disciplinada, vigiada, "torturada", situada num corpo também vigiado por médicos, fisioterapeutas, educadores físicos, nutricionistas, personal trainner. São as maquinarias da educação agindo sobre a alma

\footnotetext{
${ }^{1}$ Utilizo neste artigo o termo "identidade" a partir de Stuart Hall "para significar o ponto de encontro, o ponto de sutura, en tre, por um lado, os discursos e as práticas que tentam nos 'interpelar', nos falar ou nos convocar para que assumamos nossos lugares como os sujeitos sociais de discursos particulares e, por outro lado, os processos que produzem subjetividades, que nos constroem como sujeitos aos quais se pode 'falar'" (HALL, S. Identidade e Diferença: a perspectiva dos estudos culturais. Rio de Janeiro: Vozes, 2014, p. 108)., p. 111).

${ }^{2}$ HALL, 2014, p. 108.

${ }^{3}$ Para Foucault, governamentalidade é “o conjunto constituído pelas instituições, procedimentos, análises e reflexões, cálculos e táticas que permitem exercer esta forma bastante específica e complexa de poder, que tem por alvo a população, por forma principal de saber a economia política e por instrumentos técnicos essenciais os dispositivos de segurança" (FOUCAULT, M. Microfísica do poder. 16. ed. Rio de Janeiro: Graal, 2001, p. 291)

4 A odontologia de mercado caracteriza-se quando a base biológica e individual articula-se à transformação dos cuidados de saúde em mercadorias, solapando a saúde como bem comum sem valor de troca e impondo-lhes as deformações mercantilistas e éticas sobejamente conhecidas (NARVAI, Paulo Capel. Odontologia e saúde bucal coletiva. São Paulo: Hucitec, 1994).
} 
dos cidadãos, como afirmou James Donald, uma hibridez humano/máquina ${ }^{5}$. Nessa perspectiva, a boca ganhou novas representações e um novo domínio discursivo.

A beleza do sorriso e da boca vai mudando, envolvendo as dinâmicas sociais, as rupturas culturais, as novas configurações de gênero e de geração. Há, principalmente na cultura ocidental contemporânea, dois espaços que se afastam um do outro, que separam os sorrisos delicados, geometricamente delineados, dos sorrisos escurecidos e amarelados, anatomicamente incorretos, falhos, cheios de fissuras, de doenças e de ausências de dentes. Sorrisos que, para a odontologia de mercado, devem ser contidos, ou eliminados, em prol de dentes brancos, "porque há perigo para a sua bella dentadura em usar qualquer pasta dentifrícia annunciada. Eu aconselho sempre o uso da pasta Synorol pela manhã e à noite" que traz o sorriso branco como acessório indispensável de moda ${ }^{6}$. Para muitas mulheres casadas, cuidar bem do sorriso é uma questão de preservar o seu casamento, afinal, “digam-se a Eros repugnam dentes artificiais os maridos cujas esposas os têm metidos na boca"7.

No entanto, dentistas de diversos países perceberam que, com o crescimento do mercado e do número de profissionais, era necessária a criação de uma federação para congregar e para normatizar, para fazer circular ideias e projetos que integrassem e unissem, no Continente Americano, os odontólogos formados nas diversas faculdades que emergiam nos países. É sobre essa temática que iremos confeccionar este artigo.

\section{A BOCA EM DISCUSSÃO: A EMERGÊNCIA DA FEDERACÃO}

Com a finalidade de congregar e conectar profissionais, saberes e ideias em torno da saúde bucal e de seus conhecimentos correlatos, emerge na década de 10 do século XX a Federação Odontológica Latino-americana (F.O.L.A.), uma organização de profissionais odontólogos do continente americano ${ }^{8}$, uma instituição científica que desempenhou e

\footnotetext{
5 DONALD, J. Liberdade bem regulada. In: SILVA, Tomaz Tadeu da. Pedagogia dos monstros - os prazeres e os perigos da confusão de fronteiras. Belo Horizonte: Autêntica, 2000, p.94.

${ }^{6}$ ESTEVES, F. Em que edade devemos tratar os dentes das creanças? Revista Vida Doméstica. Rio de Janeiro, dezembro de 1928, p.8.

7 REVISTA CARETA, Rio de Janeiro, ed. 2543, 1936, p.16.

8 Hoje, a instituição com mais 85 anos de vida institucional, está conformada pelos 21 países da Região e representa aproximadamente 350 mil odontólogos, quase $50 \%$ do recurso humano mundial.
} 
desempenha importante papel na elaboração do campo médico-odontológico na América Latina e na constituição da identidade profissional. Sua proposta de criação remonta ao início do século XX, quando, em 1909, a Revista Dental, órgão oficial da Sociedade Odontológica do Chile, iniciava um movimento de circulação de ideias com o objetivo de congregar e unir o que na época foi denominada de "família latino-americana da profissão", mas também com fins de disciplinarização, normalização, legitimação de saberes e práticas e controle dos corpos.

A federação surge, portanto, como resultado de um processo educativo e de transformações histórico-culturais, de mudança na postura dos dentistas e na necessidade da criação de ligas e associações trabalhistas, inserindo-se na ideia de que "os conceitos de um campo científico devem ser analisados tomando-se por referência o solo político e social que o

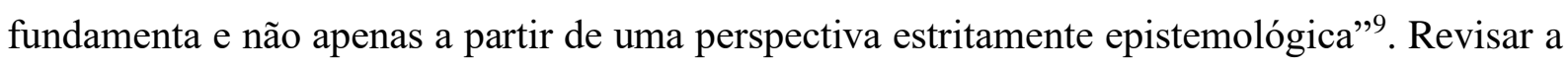
profissão e sua história era necessário, tornando-a autônoma e independente do campo da medicina.

Além disso, é preciso deixar claro que, desde o início do século XIX, com o crescimento populacional e consequentemente do número de profissionais atuando nas diversas práticas de cura (médicos, parteiras, farmacêuticos, dentistas), aumentou a necessidade de controle mais específico. A instituição das políticas de atuação do dentista deve ser analisada dentro desse quadro e sob este parâmetro: a urgência de organizar e regular as práticas de cura nos países ${ }^{10}$, em um momento marcado pela expansão e transformação do mercado de consumo de serviços odontológicos, associadas à disseminação da cárie dentária, na primeira metade do século XIX. Some-se, ainda, a existência de condições técnicas e econômicas fomentadas pelas escolas dentais, a proliferação de grupos distintos de praticantes de odontologia, as disputas pelo controle do mercado de serviços odontológicos, o desenvolvimento de uma noção utilitária da odontologia e a luta para obtenção de reconhecimento público. Em relação ao reconhecimento público, a profissão do dentista necessitava ampliar o prestígio social e o prestígio do saber,

\footnotetext{
${ }^{9}$ OLIVEIRA, C. Eugenizar a alma: a constituição da euphrenia no projeto de higiene mental voltado à infância da Liga Brasileira de Hygiene Mental. Rev. Latinoam. Psicopat. Fund., São Paulo, v. 14, n. 4, dezembro 2011, p. 629.

${ }^{10}$ WARMLING, C.; MARZOLA, N.; BOTAZZO, C. Da autonomia da boca: práticas curriculares e identidade profissional na emergência do ensino brasileiro da odontologia. Revista Manguinhos, v.19, n.1, jan.-mar. 2012, p. 183.
} 
além de circular a imagem de uma profissão ligada ao alívio prestado aos que sofrem com algum incômodo bucal e à necessidade de ser útil socialmente.

A ideia de associar os profissionais dentistas da América Latina também foi acolhida pela Revista Dental de Havana (Cuba), despertando o interesse de diversos dentistas que recepcionaram e aplaudiram tal iniciativa, vendo como um marco para a sua carreira e uma forma de dar visibilidade social e política à profissão, buscando o fortalecimento de sua corporação, a defesa de sua graduação e do mercado de trabalho, constantemente "invadido" por empíricos e práticos. A Federação estaria situada naquilo que Foucault denominou de "biopolítica", ou seja, a biopolítica é, antes de tudo,

[...] uma estratégia, ao mesmo tempo, de proteção e de maximização desta força: a vida dos indivíduos vale doravante muito, não em nome de uma pretensa filantropia, mas porque ela é essencialmente força de trabalho, isto é, produção de valor. A vida vale porque é útil; mas ela só é útil porque é, ao mesmo tempo, sã e dócil, ou seja, medicalizada e disciplinarizada ${ }^{11}$.

Analisar a história dessa federação enquanto uma instituição biopolítica e, também, como instância educativa, implica investigar o que se passa no seu interior, problematizando elementos que conferem identidade profissional, ou seja, aquilo "que lhe confere um sentido único no cenário social do qual fez ou ainda faz parte, mesmo que ela tenha se transformado no decorrer dos tempos"12.

Aos poucos, odontólogos de diversos países, a exemplo do Brasil, aderiram à ideia de criação de um órgão que pensasse não somente a profissão odontológica, mas reunisse saberes em prol da sociedade de forma a aproximar conhecimentos e circular ideias educativas em torno

\footnotetext{
${ }^{11}$ REVEL J. Nas origens do biopolítico: de vigiar e punir ao pensamento da atualidade. In: GONDRA J. G.; KOHAN, W. O. (Org.). Foucault 80 anos. Belo Horizonte: Autêntica, 2006, p.55-56.

${ }^{12}$ GATTI JUNIOR, D. A história das instituições educacionais: inovações paradigmáticas e temáticas. In: ARAÚJO, J. C. S.; GATTI JUNIOR, D. (Org.). Novos temas em história da educação brasileira: instituições escolares e educação na imprensa. Campinas: Autores Associados; Uberlândia/ MG: EDUFU, 2002. p. 20.
} 
da saúde bucal e das novas tecnologias emergentes, como próteses, pivots, dentaduras de vulcanite ou acrílico, coroas de ouro, aparelho para os dentes e suas variáveis.

Dessa forma, a FOLA, ao fazer circular um pensamento odonto-sanitário, ganhou, aos poucos, o estatuto de um "manual educativo", no qual os artigos e orientações publicados por meio de seus boletins veiculavam narrativas sobre as novas descobertas e os novos tratamentos sobre a saúde bucal da população de diversos países, tornando-se, portanto, um espaço de educação de corpos e mentes e o dentista um educador de sentidos, de posturas, de maneiras corretas para se livrar da dor e das doenças bucais.

Os discursos que circularam ${ }^{13}$ em jornais e revistas latino-americanos de odontologia construíam cenários de esperanças no novo século, ao mesmo tempo em que davam visibilidade à caótica paisagem da saúde pública nos países, descritos como territórios habitados por gente doente e por uma série de doenças que molestavam a população. As ideias sobre a Federação começaram a se circular e ganharam adeptos em diversos países da América Latina. Em 1910, quando da convocação do Congresso Panamericano de Medicina e Odontologia, que se realizou em Buenos Aires (Argentina), houve a proposta de fusão ou união federativa dos países latino-americanos visando à constituição de uma federação odontológica. Para tristeza de todos os congressistas, não houve quórum necessário para realizá-la, já que estavam presentes somente as representações de três países: Argentina, Chile e Uruguai.

No entanto, para adiantar os trabalhos e ampliar o movimento de congregação de profissionais, foram designados os doutores Juan Nicasio Etchepareborda, do Círculo Argentino de Odontologia, Leandro Cañizares, cubano, e Luis de la Barra Lastarria, da Sociedade Odontológica de Chile (autor da moção da união federativa), para prepararem um projeto a ser apresentado no próximo Congresso, que seria realizado no Rio de Janeiro $(1913)^{14}$. Tal projeto visava regularizar a organização e o funcionamento sociais do ponto de vista profissional e social, despertando, também, os seus membros sobre a importância de um lugar para se pensar enquanto corpo profissional e enquanto ator social, inserindo em conjunturas

\footnotetext{
13 Acerca dos conceitos de produção, circulação, distribuição e consumo de informações, estamos dialogando com Roger Chartier. Para Chartier, a relação entre produção de discursos e leitores não é apenas uma relação de imposição da informação dominante, de assujeitamento, mas sim uma relação de negociações, aceitações e recusas do leitor (CHARTIER, R. Práticas de leitura. São Paulo: Estação Liberdade, 1996). ${ }^{14}$ Em 1913, o Rio de Janeiro foi sede do I Congresso Panamericano de Odontologia que se realizou na Biblioteca Nacional.
} 
econômicas e higiênicas distintas. Investidos de autoridade científica, os doutores acima apresentaram o projeto, porém, mais uma vez, para dissabor dos presentes, durante o Congresso carioca não houve o número adequado de representantes, o que precisou ser postergada a possibilidade de criação de uma organização americana desses profissionais.

No Clube da União, em Santiago do Chile, continuaram sendo manifestadas as opiniões para a criação de uma organização profissional dental. $\mathrm{O}$ discurso e as práticas de poder dos atores políticos mobilizaram um conjunto de saberes para qualificar ou desqualificar códigos e comportamentos sociais, com a finalidade de corrigir as "anomalias" que se instauraram nas nações, como o crescente número de teguas ${ }^{15}$ ou empíricos e de dentistas práticos que ganhavam visibilidade entre a população. Uma preocupação é que a odontologia ainda não gozava, em alguns países da América Latina, do merecido respeito por parte do Estado, o que contribuía para que a profissão fosse "invadida" por charlatães: "Nas legislações de todos os países civilizados, encontramos penalidades para o exercício ilegal das profissões que interessam a saúde pública"16. Alguns países, como o Brasil, ainda não reconheceram a "necessidade da efetiva repressão ao exercício ilegal da Odontologia, isto porque a nossa profissão ainda não mereceu dos governos o reconhecimento do seu valor e da sua significação, trabalhando com os seus elementos, ao lado da medicina, pelos altos interesses que a saúde pública envolve" 17 .

A ética profissional e o cuidado com a imagem do dentista graduado eram recorrentes entre os defensores de uma federação em nível de América Latina, algo que ficou evidente durante o II Congresso Latinoamericano de Odontologia (1925) que, em sua abertura, declarou ser necessária uma legislação uniforme da profissão na América Latina e a repreensão absoluta

\footnotetext{
${ }^{15}$ A palavra tegua é um "colombianismo" que remonta aos tempos pré-colombianos. Tal palavra é aplicada ao praticante da dentística (ou da medicina) sem título porque adquiriu empiricamente seus conhecimentos. A tradição medicinal dos teguas perdura até o século XIX, porém, no início do século XX renasce a tradição, com a figura de José Domingo Muñoz, camponês de Boyacá, curandeiro de profissão, que chegou a Bogotá para se dedicar ao comércio e torna-se famoso por exercê-la, restaurando novamente a tradição. A palavra tegua e logo se tornou familiar em Bogotá e depois em toda a Colômbia para nomear todos os curandeiros, que mantêm vivos o saber popular e o passado indígena e por extensão aos que praticam medicina e odontologia sem título.

${ }_{16}$ CAMPOS, J. A. da Silva. Exercício Ilegal da Odontologia. Anais do III Congresso Latinoamericano de Odontologia. Rio de Janeiro: Imprensa Nacional, 1930, p. 55.

17 CAMPOS, J. A. 1930, p.55.
} 
ao profissional clandestino, que aconselha o registro profissional com assinatura e cédula de identificação, visando o combate do charlatanismo e da clandestinidade. ${ }^{18}$

Dessa maneira, atrelados a uma perspectiva da medicina social, os odontólogos, ao estenderem o seu olhar clínico para os segmentos sociais e para os perigos que um dentista prático poderia oferecer aos pacientes, os percebeu como um organismo vivo, diagnosticandoo, identificando e catalogando as suas mazelas, as suas fraturas, as suas rachaduras, os seus problemas higiênicos. Era urgente, portanto, a criação de uma federação para pensar e discutir tais questões de maneira amiúde. Tal federação deveria traduzir seus postulados em medidas de profilaxia social e em normas jurídicas que facilitariam as relações da população em sua sintonia de ideais e interesses.

Dessa forma, os doutores Tomás S. Vareta, Germán Valenzuela Basterrica, Arturo Sierra, Carlos Bolton, Luis Azocar, Luis de la Barra Lastarria, Erasmo Escala, Germán Ugarte, Hernán Fleischmann, Vicente Real e Alberto Concha se tornaram expoentes e defensores dessa ideia, alimentando cotidianamente o desejo da constituição desse organismo regional. Foi assim que a Sociedade Odontológica do Chile, na sessão de 5 de janeiro de 1916, tomou de empréstimo tal ideia e a subjetivou como sua, designando um Diretório Provisório para a realização de um Congresso Panamericano para o ano de 1917 em Santiago de Chile, momento que seriam apresentadas e discutidas essas ideias novamente ${ }^{19}$.

No Salão Nobre da Universidade do Chile, às 18 h do dia 3 de outubro de 1917, os últimos raios do sol daquele dia testemunharam a abertura do Congresso, presidido pelo Presidente da República, Juan Luis Sanfuentes. Todos os presentes ouviram Don Domingo Amunátegui, Reitor da Universidade do Chile, que, em nome do Governo, fez a abertura do evento e expressou, em seu discurso, a honra e a glória desse acontecimento para a história da Pátria:

\footnotetext{
${ }^{18}$ ANAIS do II Congresso Latinoamericano de Odontologia, 1925, s/p.

${ }^{19}$ O Presidente Honorário do Congresso foi don Germán Valenzuela Basterrica, Presidente Executivo recaiu sobre o Dr. Alejandro Manhood e esteveo integrado pelos doutores Arturo Sierra, Luis Raveau, Pedro Labarca, Carlos Bolton, Luis Lagos, Armando Mora, Roberto Barahona, Exequiel González, Luis Vargas, Vicente Real, Carlos Mújica e el Dr.Luis de la Barra Lastarria, fundador da Revista Dental, Presidente da Sociedade Odontológica e assistentes dos Congressos anteriores realizados em Buenos Aires e Rio de Janeiro.
} 
O Congresso que inauguramos é um acontecimento digno de menção nas honrosas páginas dos anais das pátrias. Esta Assembleia contribuirá para fortalecer, sem dúvida, os laços de fraternidade que unem os povos da América, desde há vários séculos, já que nela estão representadas a maioria das Repúblicas do continente. Os anfitriões americanos trarão, resultado inevitável para a confederação sonhada por Bolívar ${ }^{20}$.

O reitor, ainda entusiasmado pela abertura do congresso e pelo valor sentimental para a história chilena, exaltou as escolas de profissão e a sua contribuição para o progresso da nação:

A Faculdade de Odontologia da Universidade do Chile teve um extraordinário desenvolvimento nos últimos cinco anos, anualmente completa a formação de numerosos e distintos profissionais. Seus alunos chegam a centenas e os doentes de quem cuida e curam milhares. Fundada em 1888, a Escola não conseguia mais fechar suas portas. Por outro lado, o feliz sucesso de seus ensinamentos mostra a necessidade de criar escolas semelhantes em outras cidades do país ${ }^{21}$.

Desenvolve-se, portanto, uma rede discursiva que envolve patriotismo e profissão, modernidade e progresso, ciência e norma, desenvolvimento de práticas de curar e de remediar a dor, enfim, são tecnologias de governo que incidem sobre "corpos em multidão" que se aliançam na formação das associações, federações e espaços pedagógicos. $\mathrm{O}$ aparato científico e a norma unem-se nos territórios escolares e, em nome da higiene do corpo, funcionam como instrumentos efetivos de gestão e controle das populações. "Foi no biológico, no somático, no corporal que, antes de tudo, investiu a sociedade capitalista". O corpo, como uma realidade

\footnotetext{
${ }^{20}$ El Congreso que inauguramos es un acontecimiento digno de ser mencionado en honrosas páginas de los anales pátrios (...) Esta Asamblea contribuirá a fortalecer, sin duda, los lazos de fraternidad que ligan a los pueblos de América, desde varios siglos ya que en ella están representados la mayoría de las Repúblicas del continente. Las anfitrionas americanas traerán, inevitable resultado a la Confederación soñada por Bolívar.

${ }^{21}$ La Escuela Dental de la Universidad de Chile ha tomado en el último quinquenio un extraordinario desarrollo, anualmente ella termina la educación de numerosos y distinguidos profesionales. Sus alumnos se cuentan por centenares y los enfermos que atiende y cura, por millares. Fundada en 1888, la Escuela ya no podía cerrar sus puertas. A la inversa, el afortunado éxito de sus enseñanzas manifiesta la, necesidad de crear escuelas parecidas en otras ciudades del país
} 
biopolítica, tornou-se alvo da medicina e dos saberes de cura. Assim como a medicina, a odontologia também é uma estratégia biopolítica ${ }^{22}$.

Mesmo sendo marcado pelo aspecto técnico, aliançado e pautado pelo paradigma positivista vigente no começo do século XX, o Congresso de 1917 tornou-se um espaço de discussão política e um cenário científico, desmitificando a ideia de uma ciência da saúde neutra, sem interferência dos sujeitos. Ademais, o congresso foi marcado, também, pela primeira "Fiesta del Cepillo de Dientes", emblemática política de saúde pública odontológica da época, que objetiva fomentar a educação higiênica bucal em casa e nas escolas. A utilização das escovas dentárias tornou-se um projeto pedagógico a ser desenvolvido nas escolas, em virtude da porcentagem de crianças (aproximadamente 70\%) que chega às salas de aula com problemas de cáries. Como se percebe, é a estatística, e não somente a clínica médica, o saber que sustenta e torna possível a biopolítica, com suas previsões, estimativas, probabilidades e medições globais ${ }^{23}$.

Assim, os chefes das clínicas dentárias escolares deveriam ampliar as propagandas e fomentar a educação higiênica, incentivando a utilização individual da escova ${ }^{24}$. A escola primária seria esse ponto de acoplagem entre os interesses da odontologia e as questões de saúde pública, um território que deveria ser caracterizado pelo governo da infância e um templo difusor de uma pedagogia de hábitos considerados saudáveis.

A infância escolar possível de normalização ganha, portanto, importância biopolítica tanto nos congressos quanto na federação. Os princípios de governamentalidade eram evidentes nas memórias e debates apresentados durante os congressos. Nesses espaços de divulgação de ciência e de progresso, "as técnicas e tecnologias de poder existentes são reposicionadas e recombinadas em diferentes arranjos de governo biopolítico" 25 . Por exemplo, nas campanhas de educação preventiva já existentes à época, a intervenção na infância era enfatizada. Dessa

\footnotetext{
${ }^{22}$ FOUCAULT, M. 2001, p. 80.

23 NESPOLI, G. Biopolíticas da Participação na Saúde: O SUS e o Governo das Populações. Disponível em:< https://www.arca.fiocruz.br/bitstream/icict/13743/2/Pol\%C3\%ADticas\%20de\%20Participa\%C3\%A7\%C3\%A3o\%20e\%20Sa\%C3\%BAde_B iopoliticas\%20da\%20Participacao\%20na\%20Saude.pdf>. Acesso em: mai. 2021, p. 65.

${ }_{24}$ Anais do II Congresso latinoamericano de Odontologia, 1925, p. 731.

${ }^{25}$ COLLIER, S. J. Topologias de poder: a análise de Foucault sobre o governo político para além da governamentalidade. Revista Brasileira de Ciência Política, Brasília, n. 5, jan.-jul. 2011, p.246.
} 
forma, regularmente os odontólogos ofereciam serviços voltados para a prevenção de cáries e de moléstias bucais, por meio de aconselhamento aos pais; assistência profilática aos escolares e tratamento e prevenção de moléstias que atacavam os escolares.

Assim, no Congresso Panamericano foram discutidos projetos para a elaboração dos Estatutos, sendo um deles apresentado pela Argentina e outro pelo Chile, de autoria do Dr. Luís de la Barra Lastarria, aprovando-se este último. Os estatutos, como dispositivos de governamentalidade, conferem legitimidade e normatividade à instituição recém-criada. Os estatutos tornaram-se documentos que moldavam, dirigiam, guiavam a conduta dos indivíduos que pertenciam à federação.

Finalmente foi elaborada a Ata de Fundação da Federación Odontológica Latinoamericana com a presença de delegados da Argentina, Bolívia, Colômbia, Chile, Equador, Guatemala, Brasil, Peru, Uruguai, e Venezuela ${ }^{26}$, sendo o Dr. Juan Burnett, do Uruguai, eleito como primeiro presidente de FOLA e presidente da comissão organizadora do Primeiro Congresso Latinoamericano de Odontologia, a ser realizado no Uruguai, em 1920. Para dar visibilidade à Federação, uma bandeira latino-americana de cinco cores foi criada (amarelo, verde, branco, azul e vermelho), o que contribuiria para tornar a federação mais visível para os que ainda não a conheciam.

É digno mencionar que a F.O.L.A tornou-se uma organização inspirada na Associação Central Brasileira de Cirurgiões Dentistas do Rio de Janeiro e da Associação Paulista de Cirurgiões Dentistas ${ }^{27}$. Assim sendo, não é qualquer profissional da dentística que pode ser membro da Federação, mas somente aqueles graduados oficialmente e que exercem legalmente a profissão em algum dos países latino-americanos. Seus integrantes podem compor o Conselho Executivo e os Conselhos Nacionais em cada um dos países integrantes.

Nos anais do Congresso realizado em Montevideo, é notório como as atas e memórias publicadas representam as noções de progresso científico e de racionalidade, sustentados por

\footnotetext{
${ }^{26}$ A F.O.L.A teve como primeiro presidente o Dr. Juan Burneo (Uruguai), como vice-presidentes os doutores. Nicasio Etchepareborda (Argentina) e Antonio Coelho Souza (Brasil), Germán Valenzuela Basterrica (Chile), Sebastián Carrasquilla (Colômbia), Eliécer Cbiriboga (Equador), Roberto Robles (Guatemala), Ernesto Febres (Peru), Luis Cariaba (Bolívia). Para secretário geral foi designado o Dr. Sector Cobas (Uruguai) e para tesoureiro Angel Guerra (Uruguai).

${ }^{27}$ Estatuto Reglamentário, aprovado na Sessão Plenária de 3 de outubro de 1925
} 
aspirações biomédicas. Em muitos casos, os profissionais dentistas anunciam que dispõem de uma série de procedimentos especializados, como curetagens e apicetomias ${ }^{28}$, extrações difíceis, banho de luz infravermelhos e violeta, uso do bisturi elétrico e colocação de prótese escultural, dentaduras com e sem abóbada palatina, além da apresentação de trabalhos envolvendo tratamento de canais, utilização de cobres nas dentaduras, ionização dos dentes sépticos e a importância dos metais coloidais na odontologia.

Em Buenos Aires, na Ata de Abertura do II Congresso Latinoamericano de Odontologia, a tônica à modernização da profissão e ao progresso científico é enfatizada pelo Dr. Mateo Quijano (Acta de Apertura, 1925). É importante destacar que a F.O.L.A procurou ser presente nos congressos, instituindo, inclusive, um prêmio para os melhores trabalhos apresentados, o que contribuía para fazer circular a ideia entre progresso científico, tecnologias utilizadas e valorização do profissional. Durante o congresso de Buenos Aires, a Federação ofereceu o prêmio “3 de octubre de 1917” a um trabalho sobre investigação da piorreia alveolar, desenvolvido pelos doutores Hermann Alessandri, Alfonso Leng e Waldo Vila, integrantes do corpo de professores da Escuela de Odontología de Santiago de Chile.

Nos I, II e III congressos, a F.O.L.A agiu de maneira muito presente, instituindo prêmios, comissões e ligas, a exemplo da Liga de Ética Profissional na América Latina (que incluía todo ato profissional particular, coletivo, institucional e periodístico relacionado com a odontologia e seu exercício legal); a Liga de Profilaxia Bucodental da América Latina. Além disso, foram instituídos durante o II Congresso a necessidade de estabelecer gabinetes dentários nas escolas primárias para serviços gratuitos prestados às crianças carentes de recursos financeiros. Some-se aos gabinetes dentários, que as clínicas escolares oficiais - normais, nacionais e especiais - devem ser de caráter exclusivamente profilático, não devendo seus titulares prestarem serviços profissionais nos ditos locais. ${ }^{29}$ De acordo com os Estatutos da Federação Odontológica Latinoamericana, os congressos e reuniões científicas internacionais seriam promovidos e supervisionados pela FOLA, considerada pelo brasileiro Frederico Eyer,

\footnotetext{
28 Apicetomia é uma cirurgia que tem por finalidade a remoção da lesão que se forma no ápice (ponta da raiz do dente). Existem dois tipos básicos de cirurgia: uma que apenas remove a lesão através de curetagem e outra que, além disso, remove o ápice da raiz. Disponível em: < http://institutodosorriso.com.br/?cont=apicetomia>

${ }^{29}$ Estatuto Regulamentário da F.O.L.A.
} 
presidente da federação (1925-1929) e coordenador do III Congresso, a "entidade suprema da Odontologia Latino-americana" e que, sob o ponto de vista "da solidariedade humana e scientífica, podemos dizer que a nossa Federação vem realizando o seu grande programma com notável sucesso" 30 .

Algo a destacar, é que a metodologia do Congresso Dental Panamericano de 1917 permitiu que tanto historiadores quanto odontólogos analisassem os artigos publicados no Encontro realizado há mais de 100 anos. A discussão dos odontológos girou em torno da técnica, no entanto, questões sociais e culturais foram tratadas naquele momento, dentre elas, as possíveis respostas para compreender a dificuldade da odontologia alcançar uma política social, tanto quanto a Medicina e a Saúde Pública. Para tanto, a Odontologia deveria ser mais acessível aos pobres, assumir uma postura política mais voltada para as questões sociais e chegar às populações das indústrias, das escolas, do exército, dentre outras.

\section{CONSIDERACÕES FINAIS}

Criada por seus profissionais, a Federação Latino-Americana de Odontologia foi pensada e organizada com o objetivo de unir a família latino-americana da profissão e se fortalecer ante os governos e à população com a realização de reuniões científicas em nível internacional para promover o aprimoramento científico e contribuir para a saúde bucal da região com propostas e iniciativas de saúde oral com incidência em público e privado. Como federação, tornou-se uma agência de regulação e de controle do corpo profissional de dentistas na América Latina, guiando, controlando e conduzindo as políticas de atenção à saúde bucal. Seus estatutos funcionam como regimes de verdade e de governamentalidade, que, de maneira capilar, atua sobre os sujeitos e suas práticas.

A F.O.L.A intitula-se uma entidade sem fins lucrativos cuja missão "é promover o engrandecimento, a dignidade e o desenvolvimento da profissão e do sindicato, tornando-se promotora da ação sistemática da organização odontológica latino-americana", favorecendo

\footnotetext{
${ }^{30}$ EYER, F. Abertura do III Congresso Latino-americano de Odontologia. Rio de Janeiro: Imprensa Nacional, 1930, s/p.
} 
uma melhor qualidade de vida para os profissionais e para a saúde bucal da população, por meio da prática dos princípios bioéticos próprios da odontologia. Portanto, insere-se no seio populacional como uma instituição que une tecnologia e governo das multidões, ciência e normatividade, progresso e biopolítica, corporeidade profissional e cuidado de si.

Atrelada à missão, a visão da F.O.L.A. é continuar a ser uma liderança para a América Latina no fortalecimento e empoderamento dos sindicatos por meio da implementação de novas estratégias de negócios e desenvolvimento organizacional para o benefício direto dos profissionais, usuários e toda a comunidade odontológica da região. Da mesma forma, consolidar a liderança como a entidade mais importante do sindicato latino-americano em nível internacional, ou seja, atuar na gestão dos corpos e na condução das condutas.

\section{REFERÊNCIAS}

Fontes

ANAIS DO II CONGRESSO LATINOAMERICANO DE ODONTOLOGIA. Acta de Apertura. Buenos Aires, 1925.

ANAIS DO II CONGRESSO LATINOAMERICANO DE ODONTOLOGIA. La obra del cepillo de dientes, 1925.

ANAIS DO II CONGRESSO LATINOAMERICANO DE ODONTOLOGIA, Buenos Aires, 1925.

ANAIS DO III CONGRESSO LATINOAMERICANO DE ODONTOLOGIA, Rio de Janeiro: Imprensa nacional, 1930.

ESTEVES, F. Em que edade devemos tratar os dentes das creanças? Revista Vida Doméstica. Rio de Janeiro, dezembro de 1928.

EYER, F. Abertura do III Congresso Latino-americano de Odontologia. Rio de Janeiro: Imprensa Nacional, 1929, s/p.

REVISTA CARETA, Rio de Janeiro, ed. 2543, 1936. 


\section{Obras Gerais}

CAMPOS, J. A. da S. Exercício Ilegal da Odontologia. Anais do III Congresso Latinoamericano de Odontologia. Rio de Janeiro: Imprensa Nacional, 1930, p. 55.

CARVALHO, C. L. A transformação no mercado de serviços odontológicos e as disputas pelo monopólio da prática odontológica no século XIX. História, Ciências, Saúde. 2006 JanMar;13(1):55-76.

CHARTIER, R. Práticas de leitura. São Paulo: Estação Liberdade, 1996.

COLLIER, S. J. Topologias de poder: a análise de Foucault sobre o governo político para além da governamentalidade. Revista Brasileira de Ciência Política, Brasília, n. 5, p. 245-284, jan.jul. 2011.

DONALD, J.. Liberdade bem regulada. In: SILVA, Tomaz Tadeu da. Pedagogia dos monstros - os prazeres e os perigos da confusão de fronteiras. Belo Horizonte: Autêntica, 2000.

FOUCAULT, M. O nascimento da medicina social. In: Microfísica do poder. 16. ed. Rio de Janeiro: Graal, 2001.

GATTI JUNIOR, D. A história das instituições educacionais: inovações paradigmáticas e temáticas. In: ARAÚJO, J. C. S.; GATTI JUNIOR, D. (Orgs.). Novos temas em história da educação brasileira: instituições escolares e educação na imprensa. Campinas: Autores Associados; Uberlândia/ MG: EDUFU, 2002. p. 3-24.

HALL, S. Quem precisa da Identidade? In: SILVA, T. T. da; WOODWARD, K.; HALL, S. (Orgs.). Identidade e Diferença: a perspectiva dos estudos culturais. Rio de Janeiro: Vozes, 2014.

NARVAI, P. C. Odontologia e saúde bucal coletiva. São Paulo: Hucitec, 1994.

NESPOLI, G. Biopolíticas da Participação na Saúde: O SUS e o Governo das Populações. Disponível em: $<$ https://www.arca.fiocruz.br/bitstream/icict/13743/2/Pol\%C3\%ADticas\%20de\%20Participa\% 
C3\%A7\%C3\%A3o\%20e\%20Sa\%C3\%BAde_Biopoliticas\%20da\%20Participacao\%20na\%20 Saude.pdf>. Acesso em: mai. 2021.

OLIVEIRA, C. Eugenizar a alma: a constituição da euphrenia no projeto de higiene mental voltado à infância da Liga Brasileira de Hygiene Mental. Rev. Latinoam. Psicopat. Fund., São Paulo, v. 14, n. 4, p. 627-641, dezembro 2011.

REVEL J. Nas origens do biopolítico: de vigiar e punir ao pensamento da atualidade. In: GONDRA J.C; KOHAN, W. O. (OrgS.). Foucault 80 anos. Belo Horizonte: Autêntica, 2006. p. 51-62.

WARMLING, C.; MARZOLA, N.; BOTAZZO, C. Da autonomia da boca: práticas curriculares e identidade profissional na emergência do ensino brasileiro da odontologia. Revista Manguinhos, v.19, n.1, jan.-mar. 2012, p.181-195. 